\title{
Future Perspectives of Health Insurance
}

\author{
by Thomas C. Ramey*
}

\section{Trends affecting the future}

The challenge facing the State and the private health insurance industry in addressing the public's need for adequate health care services and coverage is enormous. There is a predictable tension here between an ideal and a reality.

The ideal - one supported by most governments - is the idea that all citizens should have access to adequate health care.

The reality is that the demand for health care services exceeds the resources of the State.

The ideal is under great stress for three reasons :

1. Governments do not have sufficient revenues to provide "health care for all".

2. The health care governments provide is often disliked because the quality is perceived as inferior to private sector health care.

3. Governments are confronted with a future of shifting percentages, meaning fewer tax contributors to pay for a growing elderly population.

Earlier in the conference, we talked about some of the trends affecting our reality scenario :

- Longer life expectancy.

- Increase in chronic diseases.

- Inadequate services and infrastructure for the elderly.

- Better educated and more demanding consumer.

- Improved and more expensive technology.

These trends mean it will not be business as usual for governments, insurers, consumers or health care businesses. The State is having to seriously question the ideal of health care as a right.

* President, American International Healthcare, a subsidiary of American International Group; Presented to the Fourteenth General Assembly of the Geneva Association, June 16, 1987, Berlin, Germany. 
The universal dilemma for all governments is how to ration health care resources equitably. The question of equity is stretched to its furthest limit of interpretation as demands grow and resources dwindle. In this environment of difficult issues and choices the question occurs : Under what circumstances, if any, can private health insurance help address and solve some of these problems?

\section{Physicians versus businessmen}

For years two stereotypes have played against one another. The physician on the one hand, the businessman on the other. The physician was the untouchable, protected by a code of ethics, exclusivity and an exalted status. The businessman, on the other hand, was viewed as an individual whose only concern was for profit and business success.

The State, by and large, protected and perpetuated the image of the physician. Protected it, that is, until costs got out of hand. The State began to realize it could no longer afford business as usual. How, then, could the State respond to these changing circumstances ? It began to seek a relationship with the businessman - the private sector. A number of solutions have been attempted through this avenue, including the following four :

1. The State contracting with private sector service companies.

2. The State permitting citizens to decide whether to commit their obligatory percent of salary for health care to a private insurance scheme or to one operated by the State (Chile).

3. The State reimbursing private insurance companies for delivery of health care services.

4. The State participating with the private sector in experimental programs.

In the specific case of the United States, stimulus by the State of the private sector in the arena of health care services ignited 20 years of change which have dramatically altered the U.S. health care scene. The consequences are new and better products, services, and management systems, as well as behavioral changes. Some of the new developments include :

1. Generation of private capital for health care (investments, public offerings).

2. Entrepreneurial innovation (surgi centers, home health care, private label products, dialysis centers).

3. Utilization and cost information and controls (medical management information systems, prior authorization, case management, concurrent review).

4. Changes in consumer attitudes (concern about nutrition, smoking, excercise, over-testing, appropriate use of pharmaceuticals).

5. Management of care innovation (HMO, PPO, IPA, contracting of private management and services by State, TPA).

6. Change in physician behavior (corporate medicine, capitation, peer review).

Many of these developments have also occured, in varying degrees, in other countries. The important point is the private marketplace can play a complementary role to the State, particularly as the State struggles with responsibility for more complicated and long term issues. However, certain ingredients are required to stimulate the private sector. 
To achieve the six areas of change mentioned above, the ingredients required were :

- Incentives.

- Innovations.

- Changes in conventional wisdom.

Proper incentives attract capital. Capital becomes available when investors see a good business opportunity and a fair return for their invested dollars. The State, if it desires to attract private capital for health care, has to create a climate to attract investment. Capital feeds and nourishes innovation.

And so we have a chain of events :

- incentives attract capital

- capital spawns innovation

- innovation challenges conventional wisdom.

One of the biggest innovations and changes in health care conventional wisdom was the concept of Managed Care. The private sector was clearly the innovator in this approach to health care delivery.

\section{Managed Care}

The managed care phenomenon of the last ten years in the U.S. reflects all of the six developments I mentioned earlier. Whether it is HMOs in the U.S., or privatization efforts elsewhere, this phenomenon has provoked insurance companies, among others, to look at management of the process of delivery of health care as a consideration for investment of resources and a goal of business development. Suddenly, insurance companies, in order to grow market share or to simply maintain position in the marketplace, have had to invest capital, employ new techniques and become involved in the process of delivering services, rather than confining themselves to activities associated with claims processing.

"Managed health care" means, in part :

- Close monitoring of utilization and cost patterns.

- Checkpoints on access to expensive and excessive services (e.g.: hospital admission), to assure medical necessity.

- Active intervention to encourage least expensive modality of treatment consistent with quality.

Semantics : Insurance + Managed care $=$ Managed Health Insurance

This is a new role for insurers. Prior to their more active involvement in managed care, insurers could have been seen as actually exacerbating the dilemma. That is, the insured would pay their premium and then expect, without restraint, (except for deductible and copayment) services to be delivered. The result was :

- insurers processed claims

- providers increased fees.

No one tried to manage the process of the providers, or the costs that were requiring reimbursement. A cost spiral began. So, it was the physicians charging what they could, and insurers reimbursing, without control or constraint, to the insured. 
The State, however, intervened in the early 1970 's in the United States to protect and propagate the managed care systems. It did this with the passage of the HMO Act. The HMO Act became a tremendous incentive to attract capital and private sector attention.

The HMO Act of 1973 encouraged further development and utilization of HMOs :

- Employers were required to permit HMOs to market to employees.

- Employers were required to contribute the same amount to the employees' HMO as to conventional insurance plans.

HMOs and their techniques had entered the scene. "Managed care" became part of the U.S. reality and lexicon as did the businessman's participation in health care delivery.

The combination of private managed health insurance working with the State achieved some of the following :

- Relieved pressure on the public sector by providing alternative systems.

- Created models for efficiency, altered provider behavior.

- Served as delivery system for the State scheme.

- Shared risk, monitoring, cost.

The past decade has provided some valuable tools and changes. What next?

\section{The future}

As we look ahead we see the future framed in spiraling costs, a growing elderly population, fewer state resources and a pervasive anxiety about how to cover the expense and demands of catastrophic care.

Already the demand for long term care products has fostered the creation of numerous cost savings and valuable businesses such as home health care and sale of generic products, to name just a couple. Additionally, the existence of the elderly as a growing market has spawned new ideas about nursing homes, retirement villages, acute care insurance policies, and joint ventures between the State and the private sector. Insurers in particular have enormous opportunities before them to create products which can be sold to people in their peak earning years in anticipation of old age needs.

Some insurers have evolved from simply focusing on straight claims processing to managing the provision of health care services. The next step will probably mean actually becoming a provider of services, especially in the case of services to the elderly. Insurers have access to the capital and experience necessary to structure products which can be sold today and provided tomorrow, such as retirement villages. Additionally, the managed care experience has and is preparing the insurer for entry into provision of services to the elderly.

Consumers are eager to find products which will enable them to protect their own futures as well as reduce the burden they will inevitably face with their aging parents. Years ago, one merely took care of the elderly at home within the family context. No longer. The growth of this concern and the market for products to address it are far ahead of offerings from the private sector. 
Catastrophic care is another area of concern. The State should concern itself with how to respond to catastrophic occurences. But its capacity to do this is constantly diminishing as in some countries it struggles to keep a nation-wide comprehensive health care infrastructure alive, trying to be all things to all people. The result is usually two-fold : (1) Citizens pay twice for health care - private insurance plus State health care taxes, and (2) the State, in traying to provide health care to all, provides less than adequate health care to most.

This is where a meeting of the minds should occur on a more rational and planned basis, with the State assuming responsibilities for catastrophic care, the indigent, and those least financially able, and the private sector assuming more aggressive responsibility for the larger income-earning segment of society.

What is already happening in health care, since the State is less able to provide health care to all, is the private sector is becoming more aggressive and expansive in what it is offering the public. In addition, the advent of AIDS and general concern about how to respond to catastrophic occurences puts even more pressure on the public sector to focus its resources on these areas and permit the private sector, out of necessity, to develop financially acceptable alternatives to the traditional State scheme and the cottage industry mentality of physicians.

I believe the following scenario reflects the agenda of the future:

\section{PROVIDERS, THE STATE, INSURERS}

\section{From the perspective of providers:}

- Physicians' reticence to marketing and advertising will be replaced by quest for market share.

- Business norms and discipline will have growing impact on how services are provided.

- As bed census has been reduced through cost containment, so will costly outpatient procedures be reduced, either by improved technology or more discretion.

- Providers will increasingly share more risk relative to renumeration for quality of services provided.

From the perspective of the State:

- Less resources, more demand means a need to encourage and facilitate private sector involvement in delivery of health care, through the provision of appropriate incentives.

- States will initiate more programs where they contract for specific services and support from private sector.

- Tort claims will be brought under control to reduce one ingredient of the cost spiral.

- States will be more exacting in the reimbursement schemes forcing more efficiencies and discipline.

\section{From the perspective of insurers:}

- They will become more involved in management of the providers of health care.

- They will, in some cases, become the actual provider of health care.

- They will be given more opportunity to develop alternative health care business due to experimentation by the State, overall reduction of State health care services, the creation of favorable tax and investment incentives, and enabling legislation. 


\section{Conclusion}

The State, regardless of the country, has either to increase revenues through taxation or attract the private sector into providing more health care and health care products. "Health care for all" simply costs too much for the State to respond to by itself without some significant change in the way revenues are raised, directly or indirectly. Given this situation, insurers will surely have tremendous opportunities to provide products and services with appropriate incentives accompanying their risks. 